\title{
To What Extent Does Destructive Cults’ Leaders Employ Mind Control Techniques to Recruit Members in Order to Achieve Their Aims?
}

\author{
Ms. Dipal Patel ${ }^{1}$
}

\section{ABSTRACT}

With the constant media attention that cultism receives today, people want to know "to what extent do destructive cults' leaders employ mind control techniques to recruit members in order to achieve their aims?” The research question was developed and inspired by several books and television shows focused on cults. This research question was then investigated by evaluating numerous researches found in online libraries, journals, podcasts, and books. The researches were then compiled and important notes were marked. All the key definitions are mentioned as well as limitations of the research methods used in order to assess cults. In order to holistically address the question all the three levels of analysis were used: biological, cognitive, and sociocultural. The concepts are further clarified with explaining two major exemplar cults: Peoples Temple and Heaven's Gate. The essay concludes that though there are some possibilities where mind control may be employed with admirable intentions, most of the evidence suggests otherwise. Moreover, individuals lose their identity in the cults. They are trained and conditioned and degraded from humans to mere pets. Cult leaders rob their members of the one thing that makes them human by entirely controlling them: higher cognitive thinking. All of them share one major trait: their need to control anything and everything. In terms of dependency, it is a two-way relationship since the members are dependent on the leader and the leader is dependent on the members as his/her power stems from the members' vulnerability. Finally, to answer the research question it could be said that to a large extent destructive cults' leaders employ mind control techniques to recruit members in order to achieve their aims.

Keywords: Leaders Employ, Mind Control, Techniques

We are constantly exposed to media that is notorious for stretching the truth. Regardless, the same media is responsible for informing us of the events occurring around the world. It is the irreplaceable means to our knowledge, but we must not fall prey to the illusion by blindly trusting this infamous method of communication. Either the final outcome it prints and advertises can be valid, reliable or the complete opposite. It can also be a mixture of both; this may be more frustrating and frightening than both of the above.

\footnotetext{
${ }^{1}$ Research Scholar, Department of Psychology. M.S. University. Baroda. *Corresponding Author

(C) 2015 I D Patel; licensee IJIP. This is an Open Access Research distributed under the terms of the Creative Commons Attribution License (http://creativecommons.org/licenses/by/2.0), which permits unrestricted use, distribution, and reproduction in any Medium, provided the original work is properly cited.
} 


\section{To What Extent Does Destructive Cults' Leaders Employ Mind Control Techniques To Recruit Members In Order To Achieve Their Aims?}

This trust issue brings us to a topic that is compelling the media to publish articles and as a result encouraging the audience to ask questions. There are movies, newspaper articles, television shows, books, etc. focused on cults and its scandalous practices of mind control. In other words, people want to know "to what extent do destructive cults' leaders employ mind control techniques to recruit members in order to achieve their aims?” Before attempting to answer the question, it is important to define mind control and cults.

\section{Mind Control}

Mind control, brainwashing, and coercive persuasion are all interchangeable terms. Unlike what people assume and as Philip Zimbardo words it, mind control is "neither magical nor mystical, but a process that involves a set of basic psychological principles" (Zimbardo, 2002). Moreover, Martyn Carruthers sums up coercive persuasion as an attempt to "force people to change beliefs, ideas, attitudes, or behaviors using psychological pressure, undue influence, threats, anxiety, intimidation, and/or stress."

In other words, mind control is employed in order to manipulate people. Why is mind control used; what do the practitioners aim to achieve through mind control? How is it practiced? Is it advantageous for both parties and does it harms the patient while benefiting the practitioner? What lies in the aftermath of mind control? All these questions should be considered before making any rash judgments. Nevertheless, the amount of evidence proving the detrimental effects of mind control overpowers that of the beneficial effects. The media appears to be emphasizing the negative side of mind control. Perhaps, it is with good reason since most human beings need to establish a sense of control. Some do it in a healthy manner while others tend to fall towards the extremes that not only harm them but also those around them. Destructive cult leaders are not the only people using mind control techniques to reach their goals. There are cases outside cultism related to mind control. Ruth's (the name is a pseudonym) dreary story described below demonstrates the darkest side of mind control.

Glenn Ross Caddy performed a case on "family pathology and the creation of madness."This study clearly indicates how Ruth's belief system was manipulated by a man and to what extent. Moreover, the factors involved in making her vulnerable such as high levels of stress, chronic sleep disruption, progressively evolving shared delusional disorder, emergence of hypnogogic phenomena, and the repetitive notion of God's messages to her are also detailed. She was manipulated to such an extent that she started to experience auditory hallucinations. As a result, she murdered her own baby under the assumption that God was testing her. The complex interplay between family dynamics and religious beliefs inculcated during childhood is also shown (Caddy, 2012). 


\section{To What Extent Does Destructive Cults' Leaders Employ Mind Control Techniques To Recruit Members In Order To Achieve Their Aims?}

Participation of several variables in Ruth's descent into madness is evident. These variables can be used to promote mind control. The Cult Information Centre lists the following as methods of mind control:

- hypnosis (frequently disguised as relaxation or meditation),

- peer group pressure (the strong necessity to belong to a community suppresses any doubts),

- rejection of old values (to increase the acceptance of new values introduced),

- met communication (subliminal messages are engraved by highlighting certain key words or phrases in long and puzzling speeches),

- verbal abuse (to desensitize),

- sleep deprivation (to increase vulnerability),

- fatigue (to increase vulnerability),

- dress codes (eradicating individuality by introducing a dress code for the whole group),

- financial commitment (to make the victim more dependent on the cult)

- finger pointing (finding faults in the outside world and other cults and hence, creating an illusion of righteousness)

- flaunting hierarch (the promise of advancement, power and salvation to promote the leader's authority)

- isolation (physical separation from the loved ones)

- guilt (exaggerating the sins)

- fear (physical and emotional threats)

- replacing relationships (pre-cult relationships are destroyed and new convenient relationships are forged) (Sunday Mercury, 1998)

The example featuring Ruth mentioned previously highlights that some traits such as high stress levels make people increasingly vulnerable to mind control. The more vulnerable the victims are, the stronger is the influence of mind control techniques. The extent to which destructive cults' leaders use some of the mind control techniques to recruit members is discussed later.

\section{Cults}

"A cult is a group or movement exhibiting a great or excessive devotion or dedication to some person, idea, or thing and employing unethically manipulative techniques of persuasion and control designed to advance the goals of the group's leaders to the actual or possible detriment of members, their families, or the community." This is one of the definitions accepted by the International Cultic Studies Association.

The age-old question of how to decide what is ethical is relevant here. Which mind control techniques are considered unethical and why? Perhaps the fact that members do not give an informed consent to be manipulated holds the answer to this, but then what should be included in an informed consent? Moreover, the moral and ethical standards would deviate as me move from culture to culture. 


\section{To What Extent Does Destructive Cults' Leaders Employ Mind Control Techniques To Recruit Members In Order To Achieve Their Aims?}

\section{Significance}

According to Paul Martin, "the most conservative estimates based on a number of surveys are that 185,000 Americans alone join a destructive cult each year. Of those 185,000, at least 25\% will suffer enduring irreversible harm that will effect their ability to function adequately in the emotional, social, family, and occupational domains.” Furthermore, other countries also have similar rates of people joining destructive cults observed in the United States of America (Martin, 1996).

Would answering the extended essay research question solve anything? Is it an attempt to understand the unknown, to eradicate the fear of the unfamiliar? Would comprehending the mechanisms of terrorist cults help the government to predict their moves? Is it nothing more than a game of chess at a legendary level? Is it a plea to encourage the rehabilitation of those under the influence of cults? Would former cult members benefit from the researches and investigations done on the topic? Should mind control be banned or is it valuable in medicine and psychiatry? Are cults purely evil or do overlapping shades of grey exist? Answering such questions may help establish how urgent it is to address the issue of cultism.

Although it is important to define cults, it is more important to understand the techniques employed to change people's belief systems. Such mind control methods are not only employed in cults, but also in politics, churches, sales, therapy, etc. If applied with the intention to cure rather than manipulate, these methods could be quite useful. These techniques pose problems when they are used without the knowledge of the person being treated. It makes the person more vulnerable (Malcolm, 2012). This being said, the fact that beneficial methods of mind control may not be equally effective in medical environments if the person being treated is aware of them should be taken into account. Also, a person with an abnormal disorder may be unable to understand the importance of such treatment recommended by the psychiatrist. Perhaps, the consent of a relative or friend could solve this problem.

\section{RESEARCH METHODS}

Since the answer to the extended essay question is based on researches published online, in journals, etc. it is important to be able to criticize them thoroughly. In order to efficiently evaluate the studies based in destructive cults, their reliability and validity needs to be measured. Distinct criteria would be required to assess the reliability and the validity. The problem lies in forming these criteria.

For example, researchers may define the term "cult” differently compared to other researchers, and this would lead to the investigation of different types of groups. Furthermore, the "dynamic relationship" between cults and the society they reside in would result in "varying levels and types of destructiveness" in the cultic groups identified for the purposes of research. The ambiguity involved in the definition of cult decreases the validity and the reliability of such 


\section{To What Extent Does Destructive Cults' Leaders Employ Mind Control Techniques To Recruit Members In Order To Achieve Their Aims?}

studies. Psychologists and psychiatrists face the same difficulties during diagnosing an abnormal disorder.

One may try to propose a universal definition of cults in order to eradicate this particular problem, but the sociocultural elements would deem this impossible. Norms in one culture may not be regarded as norms in another culture. For this reason, conclusions of any one study cannot be applied to the general population and would guide further research at best.

The benefits and drawbacks of the methods used to study cults should be known in order to evaluate the studies properly. Questionnaires and psychological tests have the benefits mentioned below:

- exposure to same stimulus for all members,

- dispensing measures is easy and economical,

- quantifiable data can be collected, and

- comprehensively researched psychological tests supply standardized norms that can help while comparing members.

At the same time they have some significant downsides. These include:

- their retrospective nature may give rise to responses of faulty or reconstructed memories (reconstructive nature of memory has been thoroughly researched by psychologists),

- their self-report method may lead to answers that show psychological factors that enhance the members' tendency to respond inaccurately or in a biased manner,

- they may not consider subdued variables like ambivalent motivations, and

- it is likely that they fail to measure what they appear to measure, especially if meticulous psychometric testing has not been done.

The controversies originating due to cults stem from three principle subjects that influence all human beings including trained scientists. These are:

- psychological autonomy,

- religion, and

- politics.

Moreover, the criticisms of cults infer:

- the human mind can be easily manipulated,

- some groups known for their psychotherapeutic, political, and religious affiliations can be detrimental, and

- the status quo should be defended against cults’ predatory nature (Langone, n.d.).

This brings us to topics that could be investigated further and studied empirically. They include answering questions such as:

- How can one identify groups that are likely to have detrimental effects on the society?

- What is the procedure to evaluate environments of cults empirically with regard to aspects of mind control? 


\section{To What Extent Does Destructive Cults' Leaders Employ Mind Control Techniques To Recruit Members In Order To Achieve Their Aims?}

- How can one evaluate the magnitude and nature of injuries that members (former and current) are likely to experience?

- How often is mind control used in cults?

- How often members within and across different cults are harmed?

- What number of existing cults is probable to inflict harm?

- What number of people is recruited?

- What number of cult members has been traumatized (physically or mentally)?

- What is the efficiency of remedial attempts? (Langone, 1999)

Clearly, all the questions cannot be answered in one go. With time, the questions as well as answers may change or develop.

\section{Three Levels of Analysis}

In order to evaluate the research question holistically, it is essential to consider all the three levels of analysis: cognitive, sociocultural, and biological.

\section{Cognitive Level of Analysis}

According to Nishida in 1995, members believe that their decision to join a cult was purely a result of free will and no coercion whatsoever. Mind control is described as either temporary or permanent cognitive manipulation. It is assumed to be a behavioral-compliance method that forces the recipients to accept significant alterations in their belief systems. Therefore a cult leader's aim to enforce compliance in his/her cult members is fulfilled.Nishida also investigated how the recruits' belief system is altered. He performed an empirical study and used data collected from two hundred and seventy two former members of a religious cult through questionnaires. The following were evaluated:

- content analysis of the principles led down by the leader in the cult's publications

- videotapes of the same principles being taught,

- recruiting and seminar manuals, and

- complementary interviews of former cultists.

Nishida's findings of 1994 suggest that leaders instill new belief systems based on the five schemas stated below:

1. ideas regarding seeking the purpose of one's life

2. notions of an ideal individual, society, or world

3. planned actions that are believed to be right or moral by the individual (ethical beliefs makes one susceptible to mind control because they can be altered; members are punished when they question authority or the reliability of beliefs that are sold as knowledge),

4. ideas of causal relationships in which laws of nature are dictated by history (an epistemologist may question the validity of such assumed historical facts)

5. the leader or authority decides what is right and what is wrong. 
Further content analysis indicates that restructuring the members' belief systems involves substituting the old values with new values. In addition, Nishida investigated the factors involved in retaining members and also recruiting more members through employment of mind control techniques. Factor analysis was used in order to evaluate the surveys. Situational factors that changed and retained the belief systems of members are given below:

- limited freedom,

- restraining sexual activities,

- fatigue,

- prohibition of contacting non-members

- punishments

- rewards

- time sensitive tasks and related stress

Moreover, studies also showed four forms of complex psychological factors that achieve the same purpose. These comprise of:

1. behavior manipulation,

2. information-processing manipulation,

3. group-processing manipulation, and

4. physiological-stress manipulation.

The following table explains the first two factors and related aspects in detail.

\begin{tabular}{|l|l|}
\hline Behavior manipulation & \multicolumn{1}{|l|}{$\begin{array}{l}\text { The members were conditioned; they were rewarded when they } \\
\text { fulfilled a particular task and were punished (physically and } \\
\text { mentally) when they failed to do so. The punishment gives rise } \\
\text { of anxiety levels. }\end{array}$} \\
\hline Self-perception & $\begin{array}{l}\text { When a member is given a job in the group, his/her behavior } \\
\text { and attitude towards the group is affixed. }\end{array}$ \\
\hline Cognitive dissonance & $\begin{array}{l}\text { The face strenuous condition and are prohibited access to } \\
\text { personal luxuries such as time, money or association with non- } \\
\text { members. As a result, they are vulnerable to strong cognitive } \\
\text { dissonance. }\end{array}$ \\
\hline Information-processing & $\begin{array}{l}\text { Thanipulation metaphorical pendulum between positive and negative } \\
\text { perceptions of the cult becomes biased and leans more on the } \\
\text { positive side after the membership. }\end{array}$ \\
\hline Systemization & $\begin{array}{l}\text { Beliefs are strengthened even when contradictory evidence } \\
\text { proves otherwise. Members relate their every experience to one } \\
\text { or the other principles taught by the cult leader. }\end{array}$ \\
\hline Priming effect & $\begin{array}{l}\text { Similar to how rehearsal forces a particular piece of information } \\
\text { from short-term memory into long-term memory, repetitive } \\
\text { lectures, music, prayers, and chants reinforce specific beliefs } \\
\text { and take information processing in a particular direction. }\end{array}$ \\
\hline Threatening messages & $\begin{array}{l}\text { A human being's tendency of selfish behavior is utilized by this } \\
\text { phenomenon. Intense terror of personal harm is instilled by } \\
\text { threats of supernatural power, nuclear war, etc. }\end{array}$ \\
\hline
\end{tabular}




\section{Sociocultural Level of Analysis}

Group-processing manipulation consists of the following factors (the behavior of group members is outlined for each factor):

\begin{tabular}{|c|c|}
\hline \multirow{3}{*}{$\begin{array}{l}\text { Selective exposure to } \\
\text { information }\end{array}$} & $\begin{array}{l}\text { They avoid negative evaluations; they seek positive feedback } \\
\text { after they are committed to the group. }\end{array}$ \\
\hline & $\begin{array}{l}\text { Several members keep living in the location where they used to } \\
\text { live before joining the group. }\end{array}$ \\
\hline & $\begin{array}{l}\text { New recruits are prohibited from making contact with people } \\
\text { not involved with the group; they are also not allowed access to } \\
\text { external media. }\end{array}$ \\
\hline \multirow{3}{*}{ Social identity } & $\begin{array}{l}\text { They want to be accepted among the group members; they see } \\
\text { each other as elite trying to achieve redemption for humankind. }\end{array}$ \\
\hline & $\begin{array}{l}\text { They perceive external critics as evil or morally wrong or } \\
\text { consider them ignorant. }\end{array}$ \\
\hline & $\begin{array}{l}\text { This mob mentality allows the manipulators to arouse rash } \\
\text { group behavior. }\end{array}$ \\
\hline
\end{tabular}

\section{Biological Level of Analysis}

Physiological stress factors promote inhibitions within the group. Physiological stress can be evoked by the following situations:

- acute need to attain group goals,

- fear of punishment,

- routine group life,

- channeling sexual drive into exhausting labor,

- sleep deprivation,

- undernourishment,

- $\quad$ prolonged prayer and/or meditation.

According to the research performed by Kimiaki Nishida, the implementation of psychological manipulation for matters of mind control has two critical repercussions:

1. As evident by cases of mass suicide in cults, one of the outcomes can be antisocial behavior of lethal heights, and

2. The other factor involved in the aftermath is post-exit psychological instability.

This is often observed in members who have left a cult.

Nevertheless, the second repercussion is open to debate since it could be a result of abusive cult methodology or coercive exit stresses like deprogramming. Nishida and Kuroda used surveys of one hundred and fifty seven former members' two cults: the Unification Church and Aum Synrikyo. They employed a method called factor analysis to evaluate the collected data. Results revealed that these factors can be categorized into the following groups: emotional, interpersonal, and mental distress. The factors are listed below: 


\section{To What Extent Does Destructive Cults' Leaders Employ Mind Control Techniques To Recruit Members In Order To Achieve Their Aims?}

- susceptibility to depression and anxiety,

- diminished self-esteem,

- repentance,

- problems in retaining social relationships,

- Recallingthe ways of the cult and associated feelings,

- Unease and fearfulness of sexual contact,

- emotional insecurity,

- hypochondria,

- Covertness of cult life, and

- Rage directed towards the cult.

Similar conclusions are evident in previously performed American studies on the same issue (Nishida, 2005).Nishida's studies also validate that gender differences exist in the post-exit recovery process. If measured immediately once they leave a cult, one would find that the distress and anxiety levels are higher in women compared to men. Nevertheless, Nishida also observed that women fully recovered faster than men. Moreover, non-professional counseling is effective with some forms of distress like helplessness and anxiety. On the contrary, treatment of self-reproof and repentance is not very effective.

\section{Examples}

It is fascinating how the story of pied piper and his followers could be applied to the concept of mind control. The leader leads the followers to their downfall. Both the pied piper and the cult leaders share this quality. The most charismatic leaders commanded cults like Peoples Temple and Heaven's Gate.

\section{Peoples Temple}

Jones manipulated his followers and ultimately organized a ritual of mass suicide and murder. Jones used "sex to manipulate, seduce, blackmail and dominate members of the Peoples Temple." He "ordered beating of homosexuals, forced men and women to strip in public and had a secretary arrange sexual liaisons with men as well as women." Mile Cartmell, a former associate minister at the Temple, states, "everyone had to say they were a homosexual or a lesbian" and that "Jones realized the power of sex in destroying stable family relationships." In this manner, pre-cult relationships are destroyed while new convenient relationships are forged. Clearly, isolation played a major role here with peer group pressure. Jones encouraged rejection of the member's old values in order to increase the acceptance of new values introduced.

Some cults practice communal living but in Peoples Temple, Jones made himself the only legitimate object of sexual desire." When asked "why he had sex in this way", Jones replied that he had to as it focused the followers' interest on him. Cartmell also states that Jones boasted to engage in sexual intercourse for up to six hours at a time because "it totally obliterates" the personalities of his partners. Moreover, he believes that "Jones provided underage girls to male followers to compromise them." Up to six hours of sex would ensure the element of fatigue in 


\section{To What Extent Does Destructive Cults' Leaders Employ Mind Control Techniques To Recruit Members In Order To Achieve Their Aims?}

mind control that increased the victim's vulnerability. Al Mills, former chairman of People's Temple membership, mentioned that Jones demanded homosexual and adulterous actions from the followers since they were easily manipulated or blackmailed when they exhibited feelings of guilt. With blackmail also come emotions such as fear (The Washington Post, 1978).

Reverend Jim Jones evidently used at least nine out of the fifteen techniques of mind control outlined by the Cult Information Centre: peer group pressure, rejection of old values, fatigue, finger pointing, flaunting hierarch, isolation, guilt, fear, and replacing relationships.

\section{Heaven's Gate}

Steven Hill, former member of Heaven's Gate, feels responsible for letting his wife Yvonne McCurdy-Hill fall into the clutches of the cult leader Marshall Herff Applewhite. She died due to her involvement with the cult. They had abandoned their four children in order to join the cult. Moreover, McCurdy-Hill donated \$14,000 that she had saved for retirement. This ensured that she was financially dependent on the cult. Steven Hill described the Heaven's Gate leader as "a cold, calculating, manipulating” hypocrite.

Applewhite created an illusion of free will. The members were free to leave if they wished, but there was a lot of pressure to stay. The role of peer group pressure is apparent here. The following slogan was often repeated: "Break your ties to this world." The slogan itself is a form of metacommunication. It also encourages rejection of old values, isolation, and replacement of relationships (Vick, 1997).

Applewhite used at least eight of the fifteen techniques of mind control outlined by the Cult Information Centre: peer group pressure, rejection of old values, metacommunication, financial commitment, finger pointing, flaunting hierarch, isolation, and replacing relationships.

\section{Personal Response and Conclusion}

The concept of cultism is neither entirely evil nor fully good. It resides in shades of grey rather than black or white. Nevertheless, though there are some possibilities where mind control may be employed with admirable intentions, most of the evidence suggests otherwise. In other words, mind control may have potential to be used virtuously, but it has higher potential to be misused. It is only human nature to abuse power. Moreover, mind control violates one of the basic human rights that are acknowledged universally: the right to liberty.

In order to answer "to what extent do destructive cults' leaders employ mind control techniques to recruit members in order to achieve their aims?” we have considered the research methods used, biological, cognitive, and sociocultural levels of analysis. It is important to note that one question gives rise to numerous others and that all questions cannot be easily answered. 


\section{To What Extent Does Destructive Cults' Leaders Employ Mind Control Techniques To Recruit Members In Order To Achieve Their Aims?}

The phrase "to what extent" could be evaluated mathematically if all the mind control techniques are known and listed. For example, if there are a total of fifteen mind control techniques, then considering that Reverend Jim Jones used nine of them it could be said that he employed $60 \%$ of mind control techniques. This, of course, brings forth another issue: how much of each mind control technique was employed? Moreover, each recruit may be treated differently. Some may be easily controlled while others may have proven to be comparatively more difficult to control or manipulate. This is where estimates or averages could be calculated.

Individuals in the cults do not hold significance. They may be strong together, but they are a part of the mob. They lose their individual identity. They become highly dependent on their leader and are left at his or her mercy entirely. They may as well be called hypocrites since as a group they may be different compared to other people outside the cults but all members of the same cult are the same. They are trained and conditioned, not very different to how Pavlov experimented with dogs. This implies that the members are forced to morph their identities to that of mere pets. What makes humans different from other animals is their high cognitive thinking. Cult leaders rob their members of the one thing that makes them human.

Cult leaders become what they are either due to past trauma or due to an onset of some psychological disorder. All of them share one major trait: their need to control anything and everything. It is almost as if they are addicted to power and constantly needing more. The members of the cult are dependent on the leader while the leader is dependent on the power. This suggests that the leader is also highly dependent on the members since the power lies in the members' vulnerability. Therefore, it is a two-way relationship. Finally, to answer the research question it could be said that to a large extent destructive cults' leaders employ mind control techniques to recruit members in order to achieve their aims.

\section{WORKS CITED}

\section{Online Scholarly Journal Articles}

Caddy, G. R., (2012) Family pathology and the creation of madness: a case study of mind control. The American Journal of Family Therapy, 40, 297-319. doi: 10.1080/01926187.2011.614843

Langone, M. D., (1999). Cults, psychological manipulation and society. ISKCON Communications Journal. 7.

Retrieved from http://content.iskcon.org./icj/7_2/72langone.html

Langone, M. D., (n.d.). Research on destructive cults. International Cultic Studies Association.

Retrieved from

http://www.icsahome.com/infoserv_articles/langone_michael_research_on_destructive_cults.htm

Martin, P., (1996). Cults and health. The Wellspring Messenger. Retrieved from http://icsahome.com/view_document1.asp?ID=2136

Nishida, K., (2005). Development of the study of mind-control in Japan. Cultic Studies Review. 4 (3), 215-232,

Retrieved from 
http://www.icsahome.com/logon/elibdocview.asp?Subject=Development+of+the+Study+of+Min $\mathrm{d}+$ Control+in+Japan

Zimbardo, P. G., (2002). Mind control: psychological reality or mindless rhetoric? American Psychological Association. 33 (10).

Retrieved from http://www.apa.org/monitor/nov02/pc.aspx

\section{Newspaper Articles}

Vick, K. (1997, May 4). Victim's husband details cult life 'people were brainwashed'. The Washington Post. Retrieved from http://global.factiva.com.ezproxy2.library.drexel.edu/hp/printsavews.aspx?pp=Print\&hc= All

(1978, November 25). Jones used sex to manipulate followers, ex-cultists say. The Washington Post. Retrieved from http://jfk.hood.edu/Collection/Weisberg\%20Subject\%20Index\%20Files/L\%20Disk/Lane \%20Mark/Lane\%20Mark\%20Peoples\%20Temple\%20Massacre/Item\%20198.pdf

(1998, November 8). Fear, coercion and control - tactics used to recruit members. Sunday Mercury. Retrieved from http://www.thefreelibrary.com/Fear,+coercion+and+control++tactics+used+to+recruit+members.-a060743098

\section{Online Dictionary}

Coercive Persuasion. (n.d.). In Reference.com.

Retrieved from http://www.reference.com/browse/coercive+persuasion

\section{Nonperiodical Web Document, Web Page, or Report}

(n.d.). Characteristics of a destructive cult. International Cultic Studies Association. Retrieved from http://www.csj.org/studyindex/studycult/study_whatisdescult.htm

\section{Audio Podcast}

Malcolm, L., (2012, December 2). The psychology of cults. ABC Podcast. Podcast retrieved from http://www.abc.net.au/radionational/programs/allinthemind/the-psychology-ofcults/4392444\#transcript 